\title{
COMPARATIVE ANALYSIS OF BEARING CAPACITY OF REINFORCED AND NON-REINFORCED RAILWAY EMBANKMENT
}

\author{
Josef JírA*, Jitka Jírová, Michal Micka, Jitka ŘEzníČKová \\ Department of Mechanics and Materials, Faculty of Transportation Sciences, CTU in Prague \\ * corresponding author: jira@fd.cvut.cz
}

AbSTRACT. A comparative analysis using the programme ANSYS (FEM) deals with the generation of the computation model and with the assessment of the influence of the geogrids and the vertical lime-cement columns on the bearing capacity and deformation of the railway embankment on the less load-bearing subsoil. The graphic outputs give an overview of the field layout of equivalent stresses and deformation in the construction of the railway substructure.

KEYWORDS: computation model, geogrid, lime-cement columns, embankment, subsoil, bearing capacity, deformation, equivalent (von Misses) stress.

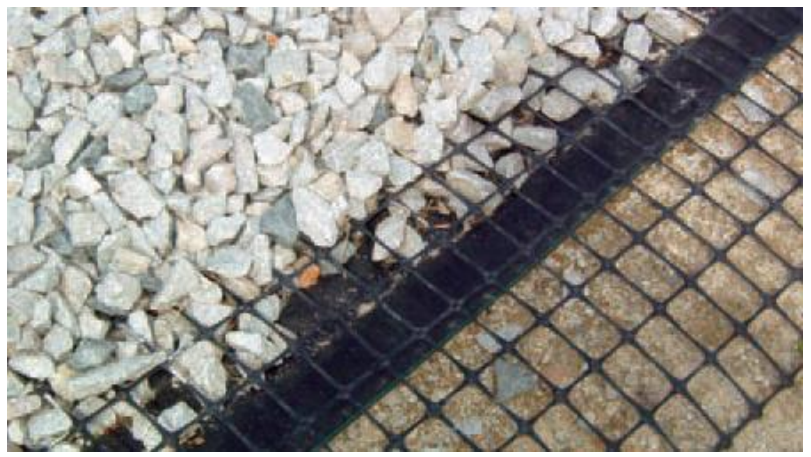

Figure 1. Reinforced geogrid Tensar SS.

\section{INTRODUCTION}

In the case of railway earthworks is a measure of the reliability and safety of the bearing capacity of the substructure and permanent way with a guaranteed track geometry, there should not be an unexpected track depression or the settlement of an embankment etc. Modernization of the existing railway routes to bear higher axle loads requires an increase in bearing capacity of the subgrade system. One possibility to increase the bearing capacity of a railway body is to introduce geogrids, see Figure 1 and 2 Vertical or inclined lime-cement columns are also used for increasing bearing capacity of the subsoil [1, 2].

By using the geogrid we can avoid the problems connected with the conventional way of extracting earth in subsoil and its substitute with loose earth of good quality. The geogrids are typical of open structures where the surface of the holes covers more than $40 \%$ of the total area. The reinforcing function of the geogrids lies in using the membrane effect, i.e. the forces in the area of the reinforcement, which have a favourable effect on tensile stresses in the soil construction.

Tensar Company's extensive experience with the modernization of the European railway corridors are

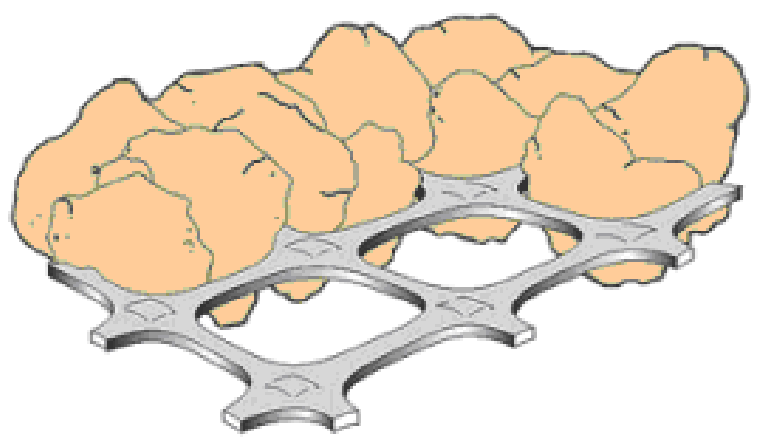

FiguRE 2. Reinforced geogrid Tensar SS.

fully and very effectively used in the railway construction in the Czech Republic. The geogrids Tensar SS are widely used in the reconstruction of the existing rail network. Effectiveness of Tensar SS geogrids was confirmed by a number of independent surveys, which conditions of non-reinforced and reinforced layer were simulated. Structural benefit of Tensar geogrids SS is to reinforce the unbound layers of railroad tracks. Granular material piled and compacted over the geogrid openings penetrating through the geogrid, so grains of soil and the geogrid fit together and creates the effect of mutual gearing between grains of soil and the geogrid. The geogrid Tensar SS creates composite together with a material bed foundation, which is effective even on the underlying ground consisting of peat or soft silt and restricts horizontal movement of the material in the ballast and minimizing the penetration of fine particles from the subsoil.

The lime-cement columns are applied in the case of building with less bearable subsoil, see Figure 3 and 4. Their task is to help in the absorption of loads, to improve the overall mechanical properties and thus to prevent future unwanted displacements of foundation and other building complications. There 


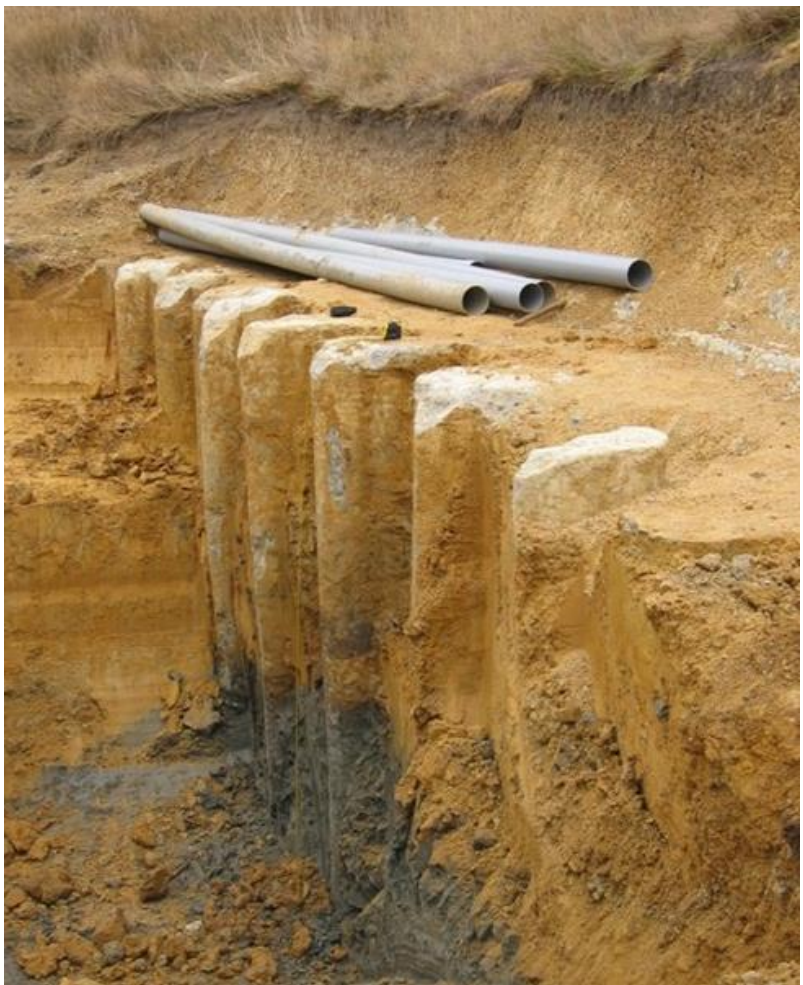

FiguRE 3. Vertical lime-cement columns - technology COLMIX [3].

are vertical or inclined columns which they are oblique to the horizontal plane at an acute angle. Length the columns prevails over other dimensions.

The manufacturing process of columns can be of two types - wet and dry process. The wet process is mixing soil with cement suspension - suspension is prepared in a central mixing pump is conveyed to the mixingdrilling tools. Lime, ash or gypsum is used in the dry method. Jet grouting is another suitable method for increasing the bearing capacity of foundation soil. The method enables also besides the creation of larger diameter columns takes small diameter drilling, which is suitable for use on construction sites are cramped conditions. The application range of lime-cement columns is large, covers an area of clay with very small grains after gravels with relatively large grains.

COLMIX patented technology belongs to the group Deep Soil Mixing (DSM). It is suitable for the stabilization of road and railway embankments and removing unwanted traffic settlement structures in low stringency (clay) soils. On the site, which is intended to stabilize, it is necessary to perform in situ analysis of soil (analysis in the field) and the result of the strength requirements and the pilots to determine the composition of the binder mixture. In case COLMIX may be used the mortar with possibility to change the cement components and calcium hydroxide (or these components may be used separately). To embed the pile to land need special equipment drill soil that is mixed with the binder mixture and form it after finishing a compact mass in the shape of a column. Interaction

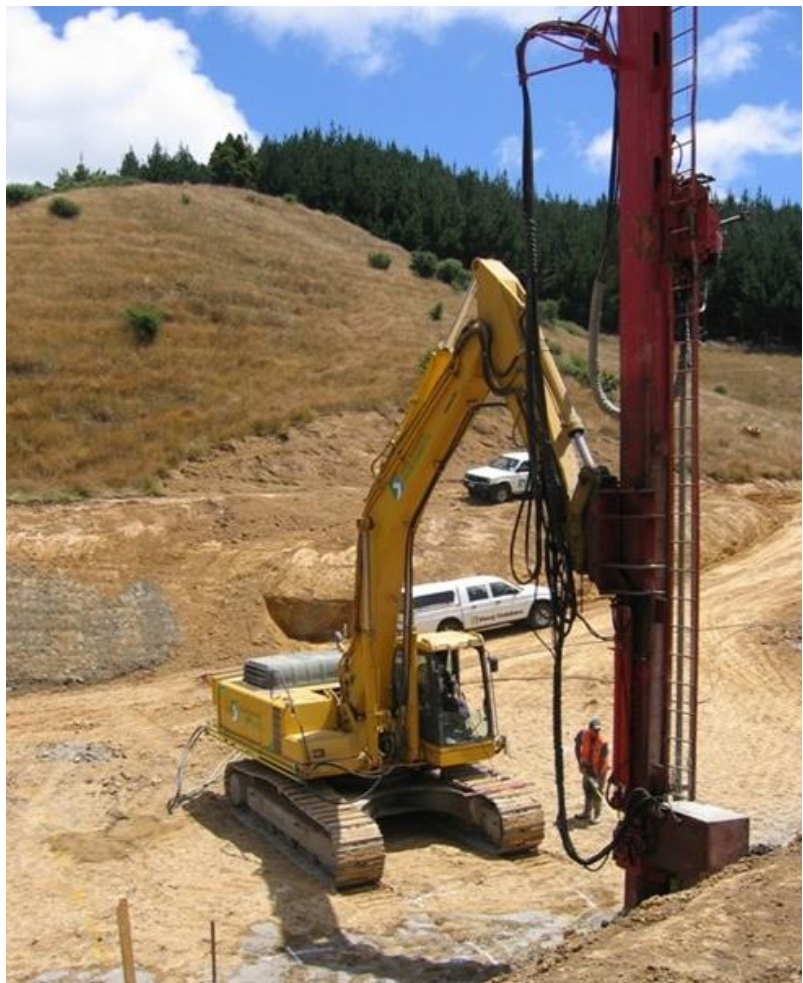

Figure 4. Vertical lime-cement columns - technology COLMIX [3].

of the columns and the surrounding soil occurs when loading to improve geotechnical properties.

Examination of the bearing capacity or stability of such adjusted constructions is usually verified in an experimental way. Experience from abroad shows that it is necessary to monitor the railway embankment settlement in the case of a non-bearing subsoil [4, 5, even if the embankment is reinforced. Therefore various experimental models are also used to study the influence of ballast bed construction on the bearing capacity and to test the reinforcing effect of the geogrids and columns.

It can be also solved by numerical methods [3, 6], mostly by the FEM (Finite Element Method). The aim of this work was to verify the numerical modelling of behaviour of a railway embankment reinforced by geogrids and lime-cement columns when using the ANSYS programme. On the model of a simple ground body the process of model creation, choice of definite elements, definition of material features, and application of contact elements, definition of marginal conditions and load and setting the parameters of computation were verified. The computation models of the reinforced and non-reinforced railway embankment were used for the comparative analysis of the bearing capacity and deformation. 


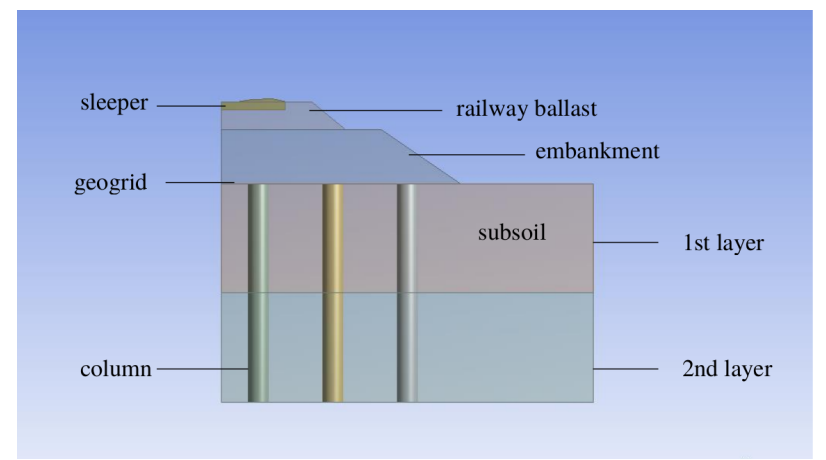

Figure 5. The scheme of layers in the model of reinforced earthworks.

\section{Computation model of REINFORCED EMBANKMENT}

\subsection{GeOMETRIC MODEL}

The finite-element method (FEM) has been successfully used to assess the performance of geosynthetics and lime-cement columns in the strengthening of soft soils. Geometric models were created for all cases in the Workbench Design Modeller.

A suitable model railway body was a need to establish for numerical calculations. The railway body in the embankment was selected for representing computational model; the scheme is compiled in Figure 5. Creating this body carried out in accordance with Czech regulations and railway literature [7]. As part of the superstructure we modelled the concrete sleepers and a gravel ballast bed. The substructure includes the embankment of impervious soil, a geogrid and columns (both for the cases where the calculated mechanical phenomena were analysed in the reinforced rail track in the case of the non-reinforced railway body is not in it). Two layers of cohesive soils having unfavourable properties were used in the base of the computational model in Figures 5 and 6 . They also interfere with columns, in the case of the reinforced model in Figure6 6

The aim of this research was to develop a spatial model. It is therefore necessary to attach the crosssection a third dimension so as to be solved the problem in 3D. For all layers of reinforced and unreinforced models (i.e. a ballast bed, an embankment, a geogrid, the first layer and the second layer of subgrade soil) was chosen length of the computational model 5,139 $\mathrm{m}$.

This value is needed for entering symmetric boundary conditions of the program ANSYS - the front and rear wall of the space model of the railway body. The axial distance between sleepers is $0,600 \mathrm{~m}$ in the ballast bed. Spatial spacing columns is a parameter chosen as a variable, depending on the analysis performed.

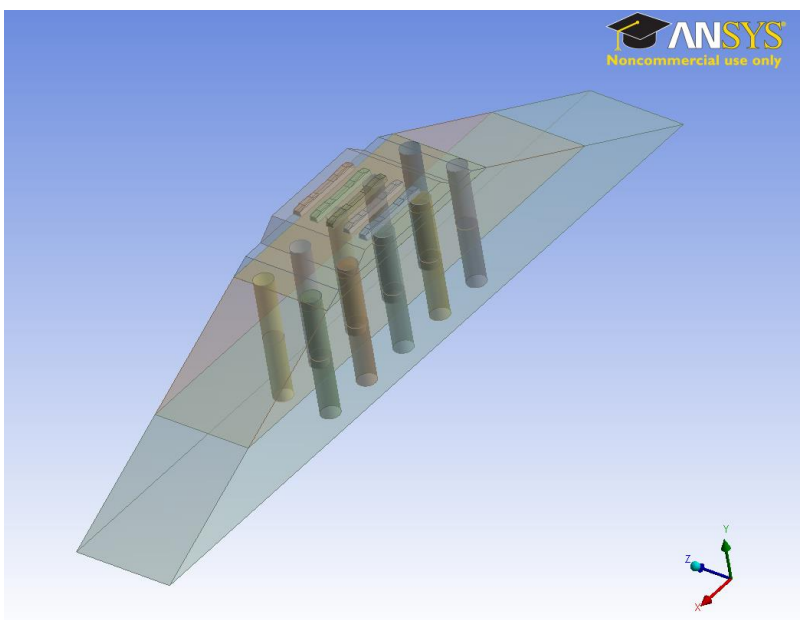

Figure 6 . The model of the embankment with a geogrid and lime-cement columns.

\subsection{MODELLING SOIL}

For modelling the properties of the embankment and subsoil material the classic DP model - Drucker Prager for geological materials is used. The material inputs are: modulus of elasticity $E$, Poisson's ratio $\mu$, density $\rho$, angel of internal friction $\phi$ and cohesion $c$. Therefore the computation is materially non-linear. This model is used most often and provides good results. The disadvantage of it is that it does not involve the possibility to express hysteresis curve for repeated load. On the contrary the advantage is that we can use tabular material standard values according to specification of soils used.

In ANSYS two more material models for geological material of plasticity can be used. The EDP model - Extended Drucker Prager - takes into account the reinforcement of the material within the loading process. The EDP CAP model supplements the EDP model with the conditions of plasticity for volume pressure and tension. The models are sensitive to proper specification of input parameters and can only be gained from laboratory tests for given material. If the material constants are for the study purposes used to convey behaviour of the soil close to the DP model, i.e. for consolidated soil, the results in transformation of the soil construction are very similar.

In all cases under investigation, we use of concrete sleepers, the ballast bed was with well grained gravel, the embankment contained gravel mixed with finegrained soils and subsoil contained clays. Material composition of the bottom structure (Figure 5 and Table 1) was considered with different material properties for the model type 1 and for the model type 2 in the calculation, i.e., that the material substructure was calculated with lower or higher modulus of elasticity (see the value in the bracket) for clay F4 and F6. Also the lime-cement columns were considered for lower quality soil substructure with the value of the modulus of elasticity of $26 \mathrm{MPa}$ or $60 \mathrm{MPa}$ (model type 2) for higher quality of soil. 


\begin{tabular}{c|l|l|l|l|l} 
Material & $\begin{array}{l}\text { Modulus of elastic- } \\
\text { ity } E[\mathrm{MPa}]\end{array}$ & $\begin{array}{l}\text { Poisson's ra- } \\
\text { tio } \mu[]\end{array}$ & $\begin{array}{l}\text { Density } \\
{\left[\mathrm{kg} / \mathrm{m}^{3}\right]}\end{array}$ & $\begin{array}{l}\text { Angle of internal } \\
\text { friction } \phi\left[{ }^{\circ}\right]\end{array}$ & $\begin{array}{l}\text { Cohesion } \\
c[\mathrm{MPa}]\end{array}$ \\
\hline \hline Geogrid & 450 & & & & \\
\hline Gravel 0/32 & 55 & 0.3 & 1950 & 30 & 0 \\
\hline Gravel 32/50 & 100 & 0.35 & 2000 & 36 & 0 \\
\hline Clay F4 & $80(90)$ & 0.35 & 1850 & 25 & 0.015 \\
\hline Clay F6 & $50(60)$ & 0.4 & 1750 & 19 & 0.016 \\
\hline Columns & $26(60)$ & 0.3 & 1750 & 25 & 0
\end{tabular}

TABLE 1. Material properties of each layer of the model type 1 and (type 2).

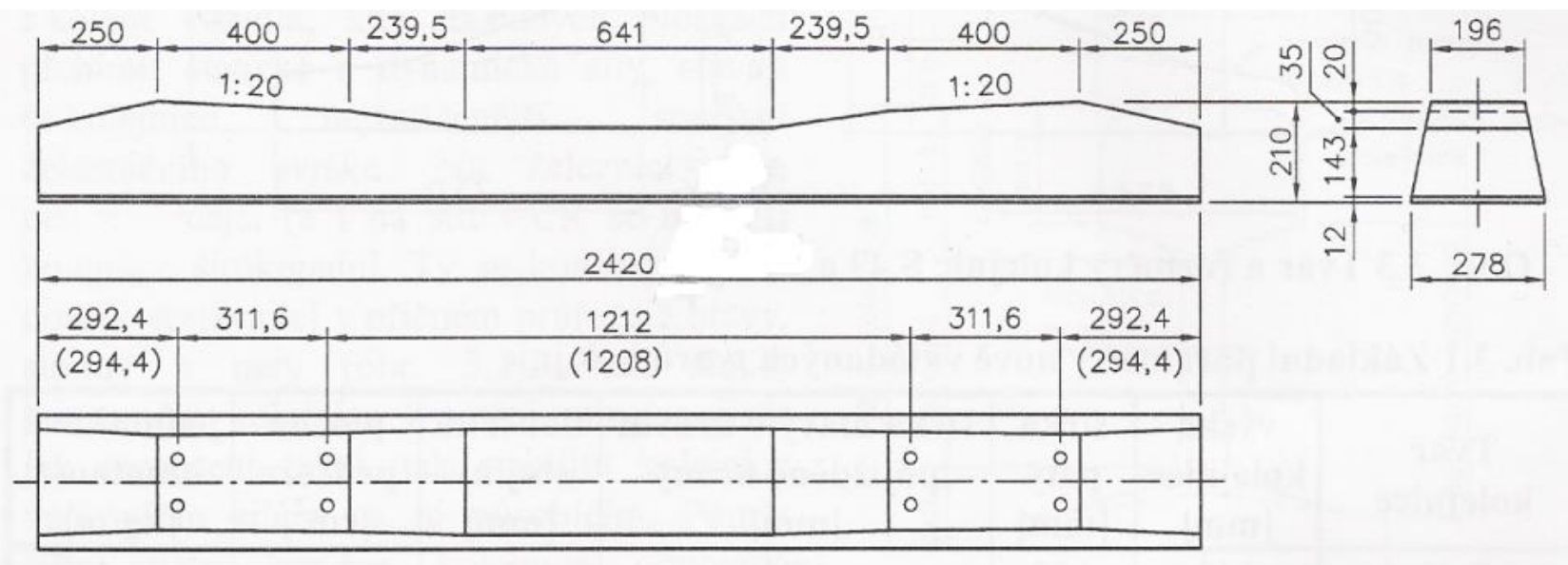

FiguRE 7 . The concrete sleeper $[\mathrm{mm}]$.

Material characteristics of the concrete sleeper in Figure 7 are: density $\rho=2500 \mathrm{~kg} / \mathrm{m}^{3}, E=20000$ MPa, Poisson's ratio $\mu=0,2$.

\subsection{FEM MODEL}

The model of the railway body and performed calculations were carried out using the Finite Element Method (FEM) - ANSYS software in version 12.1. Finite Element network was created automated methods in Workbench. Parametric studies were performed in the module ANSYS - Workbench 14 too.

All structures in the rail track in the ANSYS program were modelled as volumes. Those will then assign material properties. It is a convenient way of considering the relatively fine particles in soils. Geometrically soils are made up of prismatic volumes; volume sleepers have a specific shape and the columns are introduced as cylindrical volumes.

The reinforcement of the geogrid TENSAR SS is modelled as a thin plate of constant thickness which is mostly stressed by normal tensile forces and the bending stiffness is insignificant. The geogrid TENSAR SS30 type (Figure 8 and Table 2) was used for the comparative analysis of bearing capacity.

Contact surfaces were formed at the interface between the volumes. Their number depends on the structural complexity of the model. Other values have e.g. the model with the geogrid and columns and other are for models without one of these reinforcing elements. Contact elements of the "bonded" were used

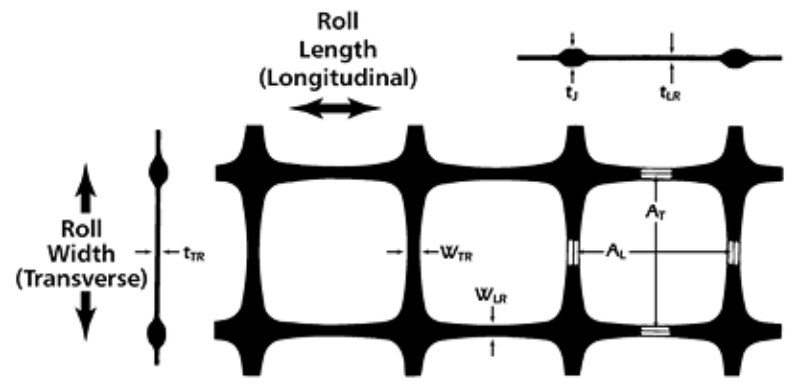

Figure 8. Shape and sizes of geogrid TENSAR SS30.

\begin{tabular}{c|c|c|c} 
Size & Value $[\mathrm{mm}]$ & Size & Value $[\mathrm{mm}]$ \\
\hline \hline$A_{L}$ & 39 & $t_{j}$ & 5.0 \\
\hline$A_{T}$ & 39 & $t_{L R}$ & 2.2 \\
\hline$W_{L R}$ & 2.3 & $t_{T R}$ & 1.3 \\
\hline$W_{T R}$ & 2.8 & &
\end{tabular}

TABLE 2. Sizes of geogrid TENSAR SS30.

in all cases. Using these contact elements prevents shearing at the contact surfaces and cannot lead to separation of two volumes.

\section{Analysis of Behaviour of REINFORCED AND NON-REINFORCED EMBANKMENT}

The verification of the computational model was done by parametric studies for four configuration model: 
(i) the embankment without reinforcement, (ii) the embankment with the geogrid, (iii) the embankment with the geogrid and the lime-cement columns and (iv) the embankment with the geogrid and the lime-cement columns sheathed the geogrid. The parametric study was conducted for the columns of diameter $d=0,6 \mathrm{~m}$ which had longitudinal and transverse distance of 1,65 m.

The load was applied to the spatial computational model as the pressure on the area sleeper. This area has sizes $0,204 \mathrm{~m} \times 0,401 \mathrm{~m}$ and settles on it the bottom rail. The axle load of the standard load train is $250 \mathrm{kN}$ and the wheel force is equal to half of this value $-125 \mathrm{kN}$, which was taken to work. The position of the wheel between the two sleepers is considered, which results in half of the wheel force per sleeper. The wheel force once repeated over a distance 2, 284 $\mathrm{m}$ - there are considered two axles.

The graphic outputs were carried out for above mentioned unreinforced and reinforced embankments and two types of material composition of the subgrade. For the total comparative analysis there are chosen graphic outputs: (i) equivalent (von Misses) stress in the subgrade, (ii) tensile stress of geogrid in the embankment, (iii) total deformation of the embankment and the lime-cement columns.

A number of parametric studies of non-reinforced and reinforced embankments were performed with different parameters, e.g. the equivalent stress (von Mises) and vertical and horizontal stresses were analysed. From all figures it is possible to see that the reinforcement of the railway embankment has a favourable effect on the bearing capacity of the subgrade. The graphic outputs give a clear overview of the field layout of equivalent stresses and deformation in the construction of the railway substructure. The maximal equivalent stress (von Misses) of the subgrade is $20 \%$ lower if the embankment is only reinforced by the geogrid, but it is $30 \%$ larger if the embankment is reinforced by the geogrid and columns. Reinforcing embankment with vertical columns has a very positive effect on the tensile stresses in the membrane of a geogrid, because heads of the vertical columns serve as a distribution platform for loaded geogrid. This arrangement allows uniform load transfer from the upper to the subsoil.

The maximal tensile stresses are in the geogrid $8 \%$ smaller and they are spread over a much smaller area. The total deformation of the superstructure (practically settlement) is lower about $2 \mathrm{~mm}$ if the embankment is reinforced by the geogrid and the columns sheathed a geogrid than for the non-reinforced embankment.

A comparative analysis shows that the reinforcement of the embankment, especially columns is important mainly for poor soils in the railway embankment, i.e. for soils with poorer material characteristics and low bearing capacity. When the more qualitative soil is used for the construction of the embankment then the reinforcement of the geogrid is sufficient to improve the stiffness of the railway embankment too. The geogrid is able to be prestressed because of activation of the membrane effect. That is usually made manually and in the tensed position the geogrid is fixed with individual clasps or with a grid with spikes infixed into the subsoil.

\section{Conclusion}

The possibility of using the ANSYS programme for modelling the behaviour of earthworks with geogrids and vertical lime-cement columns was demonstrated. The bearing capacity of the railway earthworks has great importance for railway practise. The calculation using Drucker-Prager model of soil enables through a gradual increasing in loading in load steps attain the state of stress and deformation close to the limit state at which sliding areas and big displacements. The stiffness of the soil construction, which can be derived from the values of load and vertical displacements, is an important value.

There are expected to improve useful properties of the embankment when the rail body is only reinforced by the geosynthetic grid. Consideration when evaluating the results is focused on all variants unbearable subsoil. As for sleepers, so at ballast and embankment is taken for granted that they are able to periodically transmit the resulting rail loads.

Four basic configurations of the railway body were taken into account:

- the embankment without reinforcement (labelled in Figure 14 as $E$ ),

- the embankment with the geogrid $(E+G)$,

- the embankment with the geogrid and the limecement columns $(E+G+C)$,

- the embankment with the geogrid and the columns sheathed a geogrid $(E+G+S C)$.

Computational modelling has shown the usefulness of reinforcement of the embankment by geogrids and vertical lime-cement columns, which leads to a reduction of settlement and stress state of the soil layers within the rail body. It is assumed that a rail body reinforced columns exhibits greater resistance to loading. Using vertical lime-cement columns is very significant for increasing bearing capacity of subsoil. The geogrids and the columns can be also used in the case of building a new railway.

Comparison of total deformation of the embankment for types with lower or higher values of the modulus of elasticity of the lime-cement columns showed much lower settlement values of the embankment reinforced by the geogrid and the columns with higher values of modulus of elasticity, if we compare two types of different moduli of elasticity of columns. Decreasing the values of settlement is from $15 \%$ to $19 \%$ according to type of reinforcing of the embankment. 


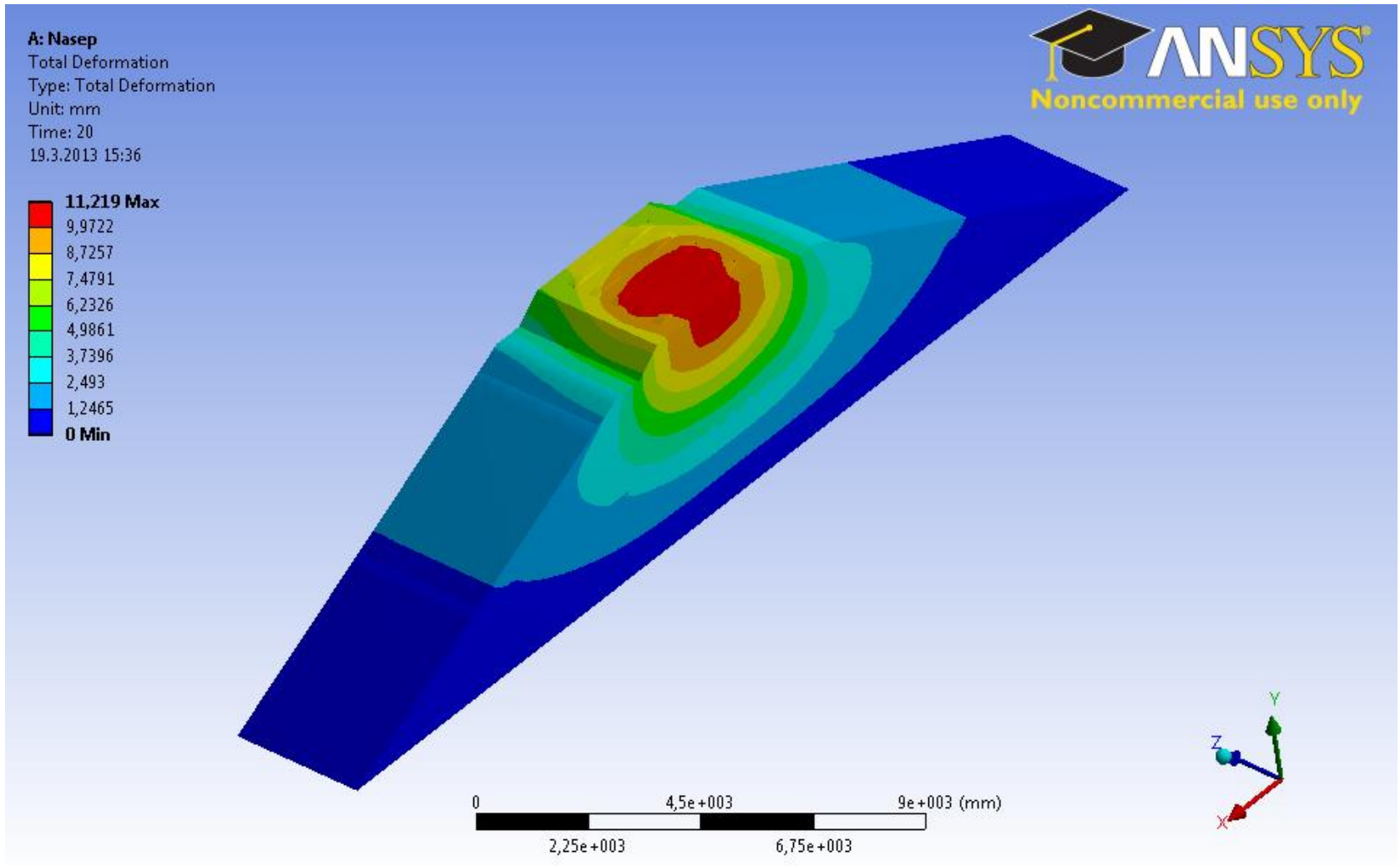

FiguRE 9. Total deformation of the non-reinforced embankment.

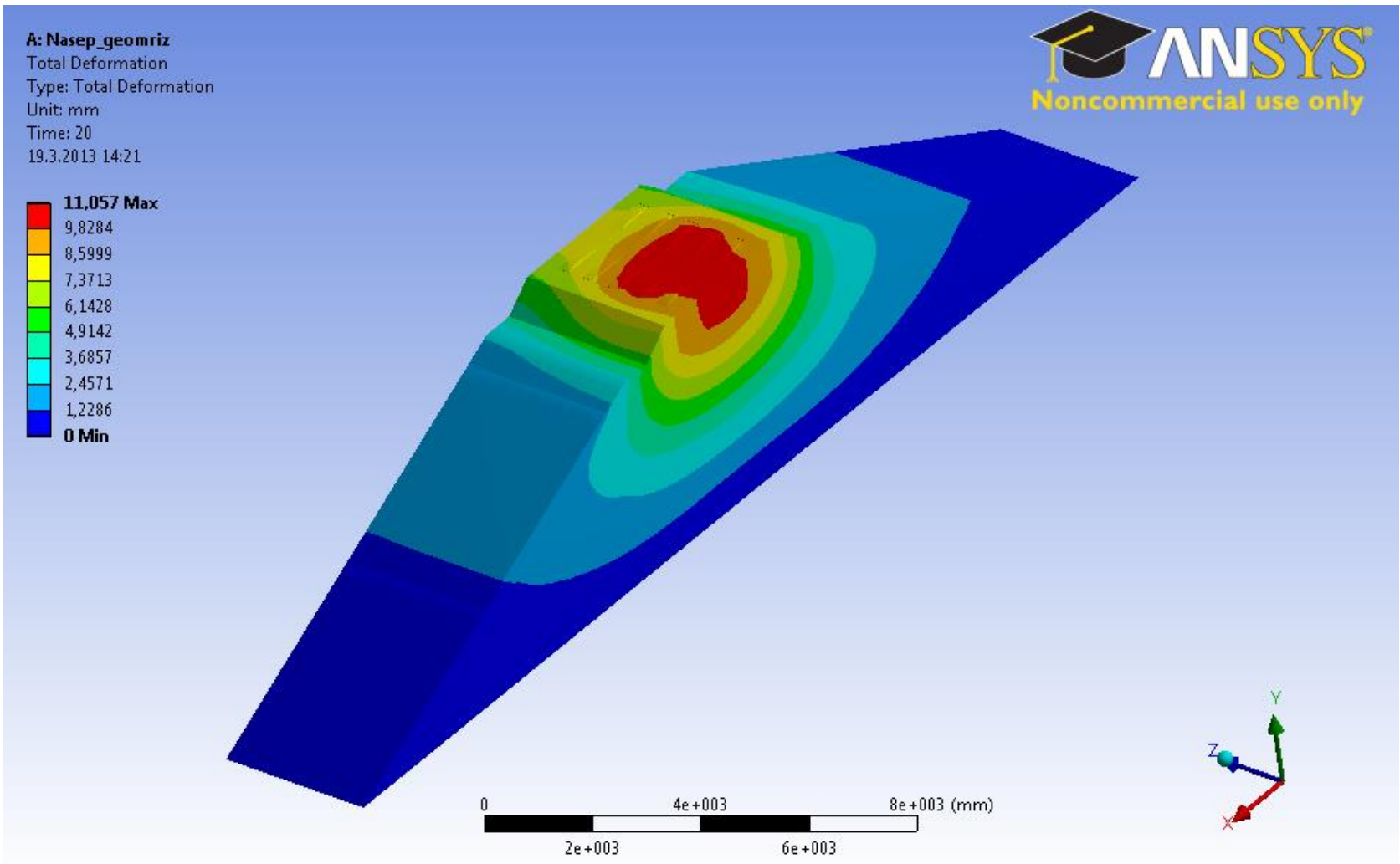

Figure 10. Total deformation of the embankment reinforced by the geogrid. 


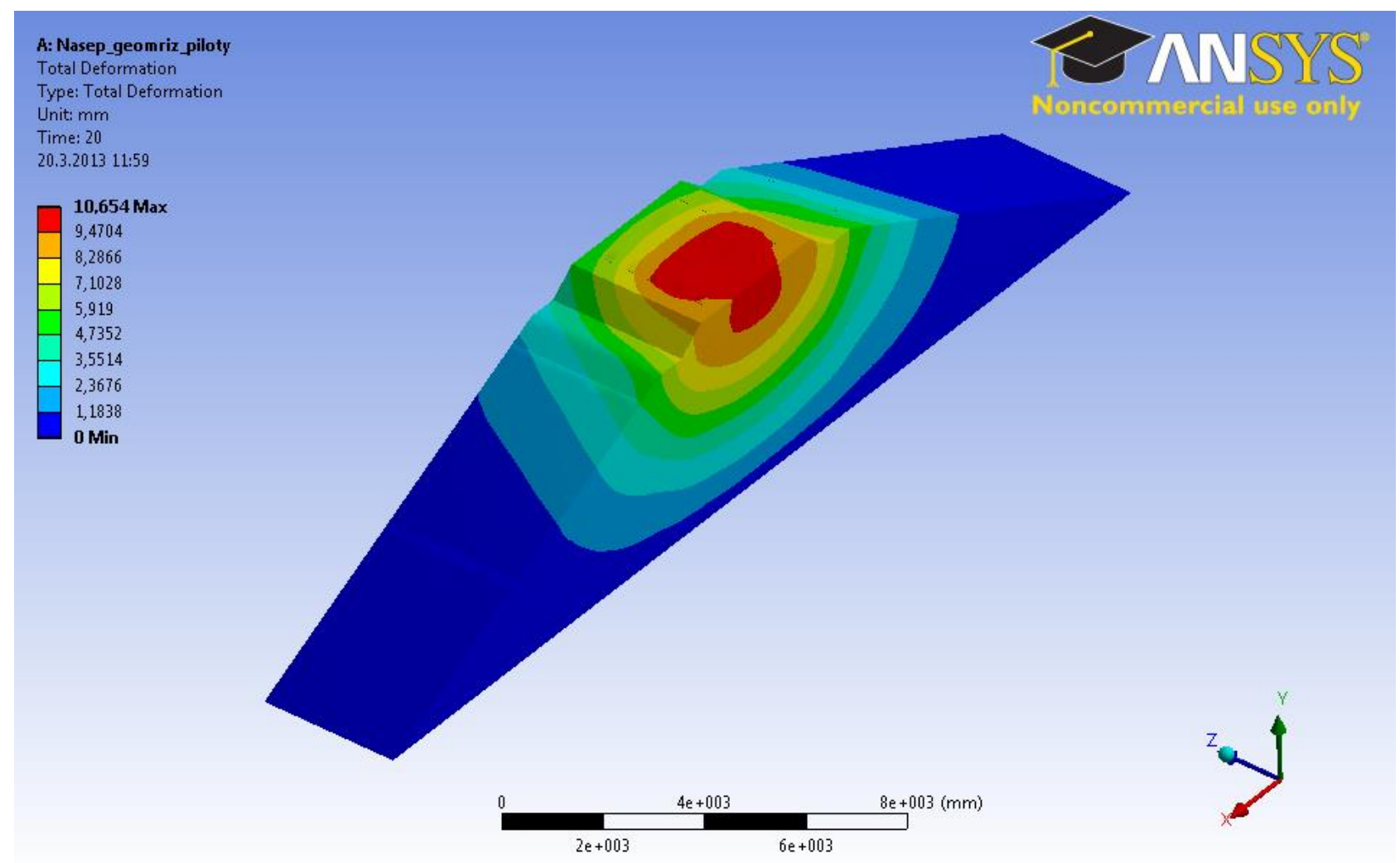

Figure 11. Total deformation of the embankment reinforced by the geogrid and the columns.

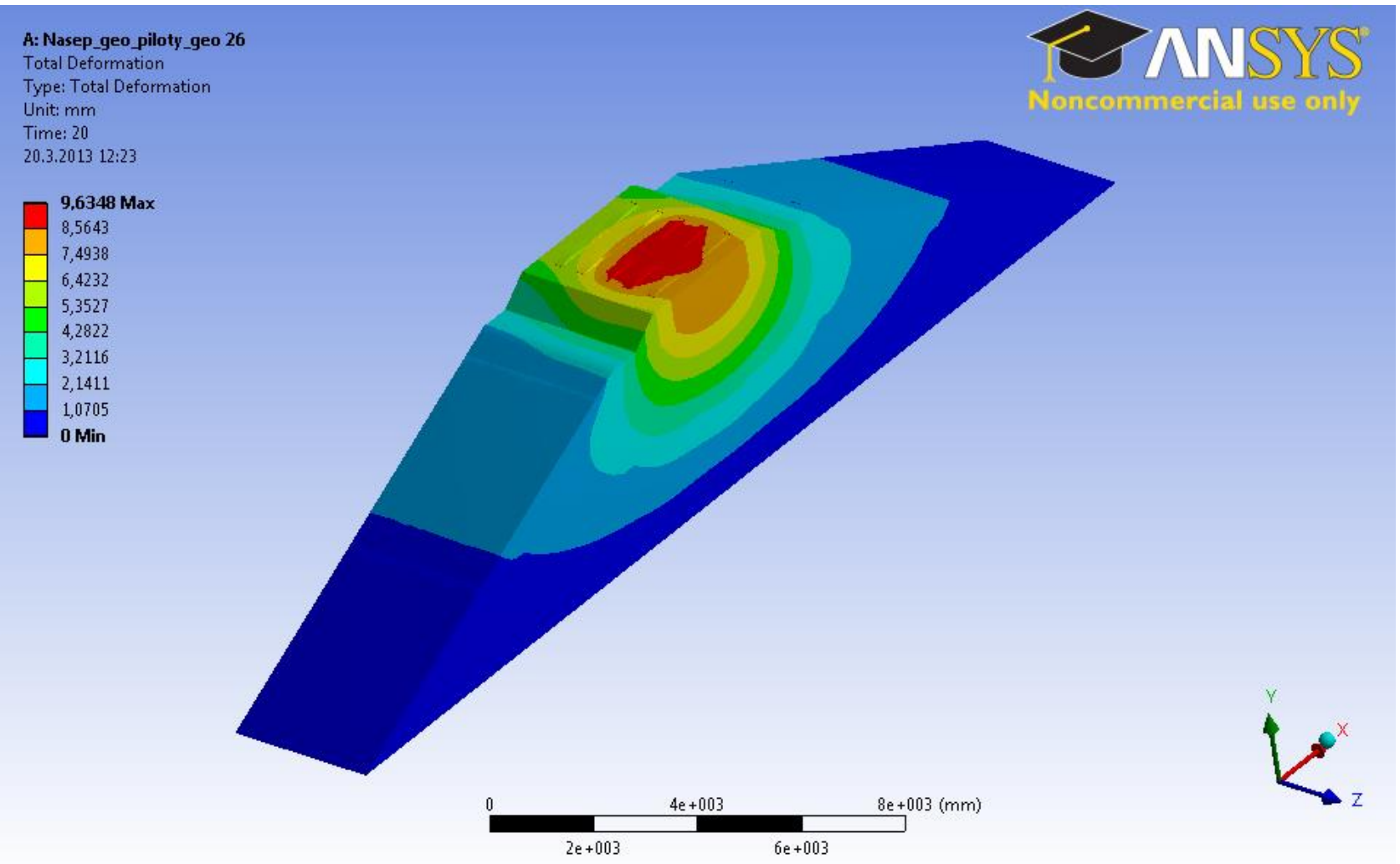

FiguRE 12. Total deformation of the embankment with the geogrid andthe columns sheathed a geogrid. 


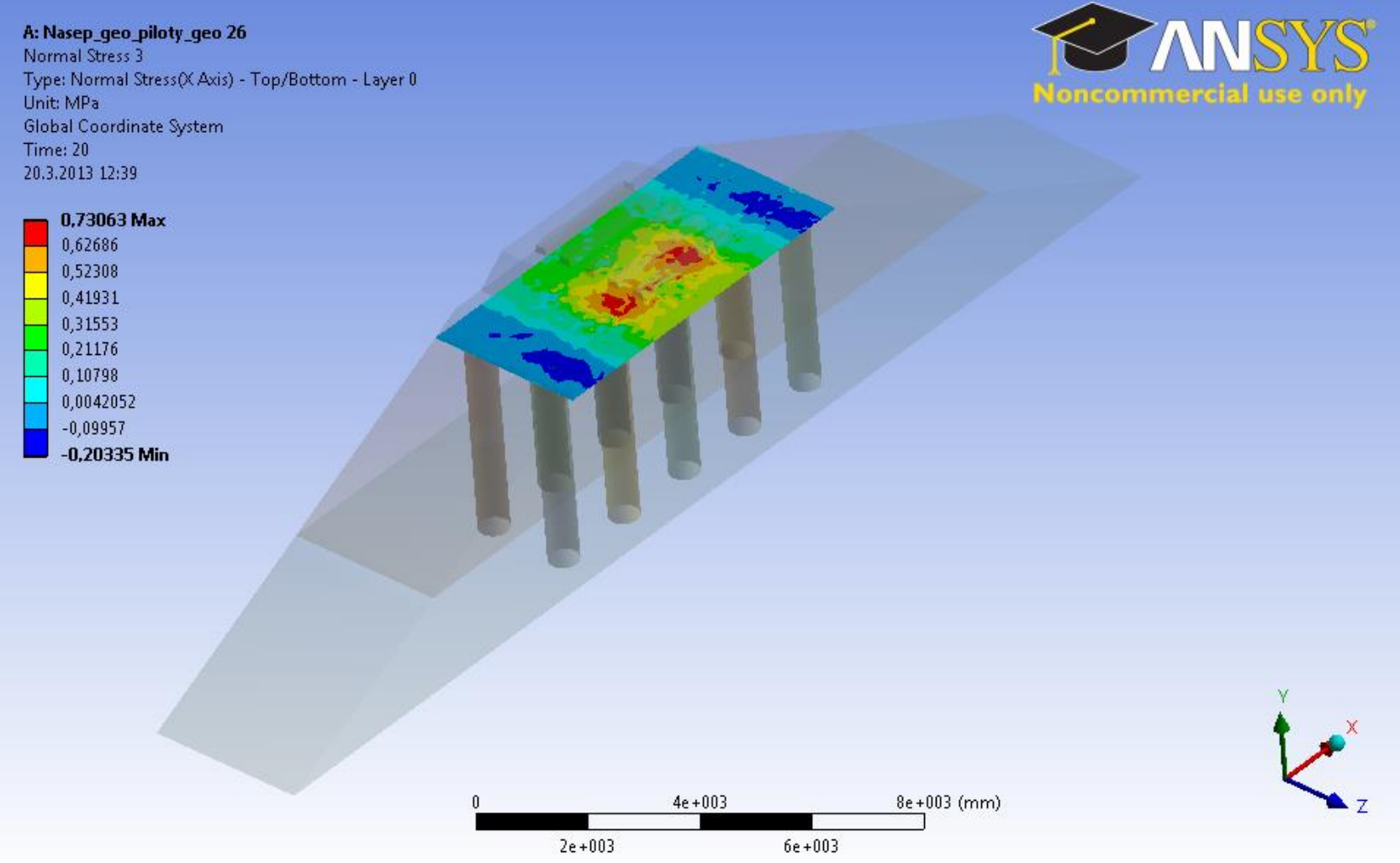

FiguRE 13. Stress field $\sigma_{x}$ of the geogrid of the embankment reinforced by the geogrid and the columns sheathed a geogrid.

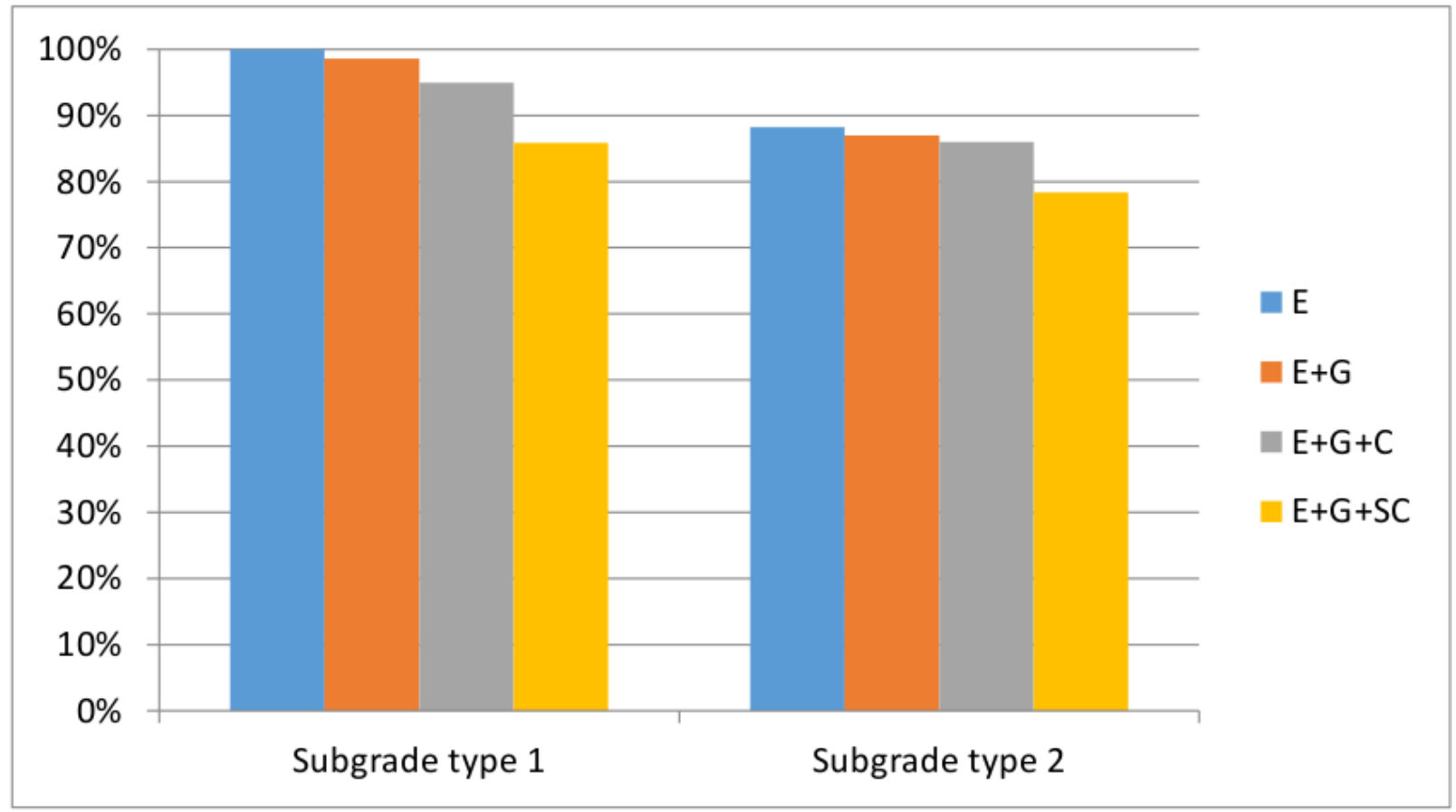

FiguRE 14. Total deformation of the embankment for all four types of structure and for two types of subgrade with various modulus of elasticity. 


\section{ACKNOWLEDGEMENTS}

This work has been supported by research plan MSM6840770043.

\section{REFERENCES}

[1] G. Femandes, E. Palmeira, R. Gomes. Performance of geosynthetic-reinforced alternative sub-ballast material in a railway track. Geosynthetics International 15, 2008.

[2] J. Zheng, B. Cheng, Y. Lu, et al. The performance of an embankment on soft ground reinforced with geosynthetics and pile walls. Geosynthetics International 16, 2009.

[3] J. Pajkrt. Space model of the part of the railway track with lime-cement columns. Faculty of Transportation Sciences CTU, Prague, 2011.

[4] L.Briancon, H.Girard, D.Poulain. Slope stability of lining systems - experimental modeling of friction at geosynthetic interfaces. Geotextiles and Geomembranes 20, 2002 .
[5] R. Holý, M. Kalika, J. Kaliková, et al. System for simultaneous object identification and sector indoor localization OIDSIL In. Proceedings of 2014

International Conference on Intelligent Green Building and Smart Grid. Piscataway: IEEE Operations Center, 2014. ISBN 978-1-4673-6123-1.

[6] O. Jiroušek, J. Jíra, O. Hrdlička, et al. Numerical modelling of the reinforcing effect of geosynthetic material used in ballasted railway tracks. Proc. IMechE, Part F: Journal Rail and Rapid Transit, 224 (F4), 2010. DOI10.1243/09544097JRRT319.

[7] Track substructure S4, Technical regulations. Railway Infrastructure Administration, state organisation. 